\title{
Sobre um encontro que conduz caminhos
}

\section{Luana Mara Pereira}

Submetido em: $16 / 04 / 2020$

Aprovado em: 26/05/2020

DOI: $10.5965 / 2358092521232020318$

1 Mestre em Educação pela Universidade Federal de Santa Catarina (UFSC). Professora do Curso de Licenciatura em Educação do Campo - habilitação em Artes e Música da Universidade Federal do Tocantins (UFT), campus Tocantinópolis. E-mail: luana.mara@uft.edu.br 


\section{RESUMO}

O presente texto trata-se de um relato que narra o encontro da autora com Márcia Pompeo Nogueira e a importância desta, tanto na vida da própria autora como no desenvolvimento de projetos que valorizam a educação dialógica e a cultura popular em diferentes comunidades. A narrativa remonta ao período de graduação da autora, na Universidade do Estado de Santa Catarina - UDESC, quando Márcia foi sua orientadora no Programa de Extensão Clubes de Teatro. Posteriormente, relata sua vivência no Curso de Especialização em Arte no Campo, na mesma instituição, no qual Marcia Pompeo foi coordenadora geral. Ao final, afirma-se que pessoas como Márcia Pompeo são de grande importância no universo acadêmico por suas práticas irem além dos muros da Universidade e conseguirem estabelecer uma relação dialógica com as comunidades contribuindo para a formação e transformação de todos(as) envolvidos(as).

Palavras-chave: Marcia Pompeo Nogueira, clubes de teatro, teatro comunidade, arte no campo, UDESC.

\section{ABSTRACT}

This text is a report that narrates the author's meeting with Márcia Pompeo Nogueira and its importance both in the author's own life and in the development of projects that value dialogic education and popular culture in different communities. To this end, it goes back to the author's graduation period at the State University of Santa Catarina - UDESC, when Márcia was her advisor in the Clubs of Theater Extension Program. Later, the author narrates her experience in the Specialization Course in Art in the Field, at the same institution, which had Márcia Pompeo as general coordinator. In the end, it is stated that people like Márcia Pompeo are of great impor- 
tance in the academic universe because their practices goes beyond the walls of the University and manage to establish a dialogical relationship with the communities, contributing to the formation and transformation of all involved.

Keywords: Marcia Pompeo Nogueira, Theater clubs, community theater, art in the field, UDESC.

Daí, só nos resta buscar a verdade bela escrevendo sobre ela, nos resta buscar a história simples do cotidiano para sermos adultos com um mínimo de criancice, sonho e esperança de um dia, enfim, não termos mágoa do que deixamos de ser, mas uma alegria colorida de sentir que ainda somos! (Maria Amélia Mano)

Aos 19 anos, após participar de uma palestra sobre arte-educação com Dan Baron em Várzea Paulista/ SP, decidi que queria ser arte-educadora. No ano seguinte, em 2005, passei no vestibular para o curso de Educação Artística com habilitação em Artes Cênicas da Universidade do Estado de Santa Catarina - UDESC. Interessada pelo teatro como linguagem potente para ações sociais e (trans)formação humana, logo no primeiro semestre procurei quem eram os(as) professores(as) que desenvolviam projetos nesta direção. Foi assim que conheci Marcia Pompeo Nogueira, que ministrava disciplinas apenas a partir da metade do curso em diante.

Tornei-me sua bolsista de Extensão no Projeto Clubes de Teatro no semestre seguinte. Fui bolsista de Marcia por dois anos, vivenciando sob sua orientação minhas primeiras experiências como arte-educadora de teatro comunidade. Marcia era uma mulher de personalidade forte e com muita firmeza em suas opiniões. Fazíamos encontros semanais de orientação, quando eu apresentava a ela meus planejamentos e relatórios. Marcia, sentada ao meu lado, em frente ao computador de mesa de sua sala, ouvia meus relatos, desabafos, inseguranças e lia atentamente o que eu lhe apresentava. Acolhia-me, orientava-me e tecia seus apontamentos e considerações sobre meus escritos. Tanto frente aos planejamentos como aos relatórios, 
fazia-me questionamentos provocativos com relação a algumas propostas ou atitudes minhas descritas, fazendo-me sempre refletir sobre a minha postura com os(as) educandos(as).

Apesar de ser filha de uma pedagoga freireana, eu mesma nunca havia estudado nada sobre relação dialógica ou relação entre educador(a) e educando(a) até então. Marcia foi muito importante para me atentar a alguns impulsos ou atitudes autoritárias de minha parte na relação com os educandos. Também me auxiliava muito em relação às estratégias didáticas e metodológicas no trabalho com o teatro comunidade. Ela tinha plena consciência de que "Não se faz pesquisa, não se faz docência como não se faz extensão como se fossem práticas neutras. Preciso saber a favor de que e de quem, portanto contra que e contra quem, pesquiso, ensino ou me envolvo em atividades mais além dos muros da universidade" (FREIRE, 2000, p. 113) e nessa direção orientava-me.

Neste período, Marcia Pompeo ministrava a disciplina de Estágio Curricular Supervisionado em Teatro Comunidade. Com ela aprendíamos sobre o ensino de teatro num contexto extracurricular. O Programa Clubes de Teatro² era, na época (20062007), uma estratégia que garantia espaços de estágio aos estudantes de graduação ao mesmo tempo em que era um espaço de ação educativa e formação em teatro nas escolas. Havia alguns grupos de teatro organizados em escolas de Educação Básica da rede pública de Florianópolis/ SC que eram parceiros do Projeto e que acolhiam estagiários no decorrer dos semestres. As oficinas extensivas dos Clubes de Teatro funcionavam semanalmente durante todo o ano letivo, alternando-se os(as) estagiários(as) de tempos em tempos.

\section{A proposta é oferecer um conjunto de atividades complementa- res, que tem o objetivo de ampliar o entendimento dos alunos [das escolas] sobre o significado do teatro. Envolve: fazer teatro,}

2 "Os Clubes de Teatro representam um conjunto de ações integradas, propostas como alternativa na formação e prática de professores de teatro, visando ao aprofundamento do significado do teatro para alunos das escolas públicas de Florianópolis." (NOGUEIRA, 2007, p. 1). 
assistir teatro, experimentar diferentes aspectos da linguagem e apresentar teatro através da participação em uma montagem. O estágio dos alunos [de graduação] envolvem a facilitação de todas essas atividades. Desta forma, os Clubes de Teatro apresentam um campo de estágio amplo e articulado para os futuros professores, de outra forma o projeto apresenta uma proposta aos desafios para o ensino do teatro (NOGUEIRA, 2007, p. 3).

Lembro-me que Marcia organizava semestralmente um encontro dos Clubes de Teatro chamado "Oficinas Intensivas" - momento ansiosamente aguardado pelos(as) participantes destes grupos de teatro comunidade. $\mathrm{O}$ acontecimento destes encontros possibilitava que, além da parte dos(as) discentes da graduação em Artes Cênicas que estagiava de forma extensiva nos grupos parceiros do projeto, houvesse também campo de estágio para uma outra parte dos(as) estudantes, que estagiava de forma intensiva. As oficinas intensivas de teatro eram oferecidas às crianças, adolescentes e adultos participantes destes grupos de teatro comunidade organizados nas escolas. O encontro ocorria tradicionalmente em um final de semana, das $9 \mathrm{~h}$ às 18h, no Centro de Artes da UDESC, totalizando uma carga horária de 18 horas.

Durante o encontro, havia uma rotatividade dos grupos nas oficinas, havendo também interação e integração entre os grupos de mesma faixa etária. O projeto oferecia a alimentação aos participantes durante o decorrer dos dois dias e, sempre que possível, havia a apresentação de um espetáculo em algum momento da programação. Ainda me recordo da euforia e felicidade estampada no semblante dos meninos e meninas que saiam de suas comunidades para participar das Oficinas Intensivas na Universidade.

Com o projeto dos Clubes de Teatro e as Oficinas Intensivas, Marcia conseguia garantir a carga-horária exigida de estágio para todos(as) os(as) estagiários(as) em teatro comunidade, fortalecer o ensino de teatro nas escolas e propiciar uma vivência artística a estudantes que, muitas vezes, nunca haviam tido acesso à linguagem teatral antes de participar dos Clubes de Teatro. 
Existiam os Clubes de Teatro que eram coordenados por bolsistas do programa de extensão com esse nome, estagiários(as) do curso de Artes Cênicas da UDESC e também os Clubes autônomos, coordenados por professores(as) e por líderes comunitários(as), que era Clubes parceiros vinculados ao programa.

Como extensionista do projeto, para ir ambientando-me tanto na lógica do teatro comunidade, como no próprio Projeto dos Clubes de Teatro, inicialmente fui incumbida de acompanhar uma dupla de estagiários, que já cursavam o último ano da faculdade, enquanto eu cursava o primeiro. No semestre seguinte, passei a ser responsável por uma turma de um dos Clubes de Teatro e a contribuir na organização e execução do encontro das Oficinas Intensivas, seguindo atuando nestas atividades até o final de meu contrato como extensionista ${ }^{3}$.

Muito me marcou este período que coordenei um clube de teatro. Ouso dizer que foi quando aprendi a dar aulas. Insegura e meio perdida, estava sozinha frente ao grupo, mas nunca desamparada. Estava sempre assistida à distância por Marcia Pompeo. Até hoje, quando faço falas que permeiem o universo do ensino do teatro ou mesmo da arteducação, ainda por vezes cito situações que vivi no clube de teatro que coordenava nessa época. As tensões entre estudantes, atritos de algum(as) deles(as) comigo em momentos pontuais, os conteúdos que eram trabalhados (ou discutidos), as estratégias didáticas... E Marcia sempre me acompanhando neste caminhar...

Marcia dava muita importância ao teatro popular, às manifestações das culturas populares tradicionais, ao Teatro do Oprimido de Augusto Boal e a outras formas de teatro comunidade, bem como à educação dialógica de Paulo Freire. Sempre que conseguia, trazia alguém para somar com seu trabalho nas disciplinas que ministrava, como foi o caso de Tião Carvalho, por exemplo, grande artista da cultura popular maranhense, que foi parceiro de Marcia em diversos momentos, sendo um deles no 
período em que eu era estudante.

Sabemos que dentro da academia muitas pessoas menosprezam este tipo de arte, julgando-a menor, de alguma forma, à arte e teatro contemporâneos. Apesar disso, Marcia tinha convicção do valor tanto da arte, como das culturas populares e seguia firme desenvolvendo seus projetos.

Defendi meu Trabalho de Conclusão de Curso em 2011, finalizando com ele minha trajetória na graduação. Dois anos depois, quando estava participando do processo seletivo para o mestrado da Universidade Federal de Santa Catarina - UFSC, fui surpreendida com um e-mail da própria professora Marcia Pompeo Nogueira divulgando o edital de seleção para o Curso de Especialização em Arte no Campo. Estava com minha mente imersa no processo seletivo do mestrado e não teria me interessado pelo edital da especialização se não me tivesse sido enviado por Marcia. Lembro-me de sentir meu coração acalentado ao ler o conteúdo do e-mail, quando ela me dizia que achava que eu deveria olhar o edital porque o curso tinha "a minha cara". O fato de ter sido lembrada por ela me tocou, então li o edital, fiquei interessada e me inscrevi no processo seletivo desta especialização também. Acabei sendo aprovada em ambas, na pós-graduação Stricto Sensu na UFSC e na Latu Sensu na UDESC, ficando com muita dúvida se prosseguiria com esta segunda, tendo em vista que, o mestrado por si só já me demandaria bastante dedicação. Todavia, dado o perfil da especialização, acabei decidindo por cursar ambos concomitantemente.

O Curso de Arte no Campo foi uma residência agrária organizada e desenvolvida por meio de uma parceria entre o Movimento dos Trabalhadores Rurais Sem Terra - MST de Santa Catarina e o Centro de Artes da UDESC. A atuação e articulação das professoras Marcia Pompeo Nogueira e Tereza Mara Franzoni foram imprescindíveis para que o Arte no Campo pudesse tornar-se uma realidade, ampliando as ações da Universidade para além de seus muros. O curso de edição única foi viabilizado através de um edital do PRONERA.

As vagas do curso foram disponibilizadas para professores de qualquer área do conhecimento que atuassem em escolas 
localizadas em áreas de acampamentos e assentamentos da reforma agrária na Região Sul do Brasil, para assentados e acampados também de toda a Região Sul que já fossem graduados e para egressos(as) de cursos de Artes. Entre os(as) participantes do curso, havia egressos dos cursos de Artes Cênicas, Artes Visuais e Música. Além dessas três categorias de participantes, somaram-se ao curso também assentados e acampados sem título de graduação, que participavam de forma modular via projeto de extensão a cada bloco de encontros.

Entre os(as) educandos(as) do curso havia pessoas de diferentes Estados (PR, SC e RS), diferentes idades (de jovens de vinte e poucos anos à idosos com mais de sessenta e cinco anos), diferentes estratos sociais (de baixa renda à classe média alta), diferentes titulações (de educação básica incompleta à doutores), diferentes níveis de experiência com artes e diferentes culturas. Eu fui selecionada entre as vagas para egressos de cursos de Artes. A pluralidade entre os(as) cursistas desta residência agrária foi extremamente rica e potente. Por sermos tão diferentes, sempre aprendíamos muito uns com os outros.

Havia uma coordenação mista, composta por professores da Universidade e integrantes do MST, que estavam o tempo todo pensando e repensando o curso (seu currículo, suas metodologias e estratégias, seu orçamento), mas a coordenação geral do curso ficou a cargo de Marcia Pompeo Nogueira.

A especialização em Arte no Campo foi um curso de Educação do Campo com o intuito de formar Arte-Educadores para atuarem nos territórios de reforma agrária, funcionando através da pedagogia da alternância 4 . Havia os módulos de Tempo Universidade (Tempo Escola), quando nos reuníamos para cursar as disciplinas ou participar de eventos acadêmicos, e os espaços entre um módulo e outro, chamados Tempo Comunidade, quando devíamos desenvolver trabalhos nas comunidades relacionando os conhecimentos estudados e os conhecimentos

\footnotetext{
$4 \mathrm{~A}$ pedagogia da alternância é uma estratégia das escolas do campo para respeitarem os calendários e demandas dos povos do campo enquanto intensificam-se as trocas de saberes entre instituição educacional e comunidade, dividindo o período letivo em Tempo(s) Escola/ Universidade e Tempo Comunidade.
} 
locais.

Foi um curso muito bonito, repleto de humanidade, solidariedade, disciplina e responsabilidade, sempre envolto de arte e poesia, pautado por um senso de coletividade e respeito. Foi quando o sentido da arte de fato floresceu em meu coração! $\mathrm{E}$ aqui não digo "sentido" de forma utilitária, entendendo a arte como uma ferramenta para algo. Não. Aqui quero dizer que foi durante este curso que a arte me atravessou, rasgou a minha carne e entrou. No percorrer desse caminho, no viver dessa experiência, é que a arte fez sentido dentro de mim, humanamente falando. Percebi seu sentido ao sentir a potência do meu sentido enquanto faço arte. Foi quando entendi o perigo da Arte: ela preenche o ser humano de sentido. Este é o sentido da arte que experienciei durante este curso.

Quando digo que "experienciei", refiro-me ao verbo derivado do substantivo "experiência", apresentado aqui por Jorge Larrosa:

um saber que não pode separar-se do indivíduo concreto em quem encarna. Não está, como o conhecimento científico, fora de nós, mas somente tem sentido no modo como configura uma personalidade, um caráter, uma sensibilidade ou, em definitivo, uma forma singular de estar no mundo que é, por sua vez, uma ética (um modo de conduzir-se) e uma estética (um estilo). Por isso também o saber da experiência não pode beneficiar-se de qualquer alforria, quer dizer, ninguém pode aprender da experiência de outro, a menos que essa experiência seja de algum modo revivida e tornada própria (LARROSA, 2004, p. 130).

A especialização em Arte no Campo me propiciou diversas experiências, mas, sem dúvida, as que mais me marcaram foram as vivenciadas na prática artística.

Durante o curso estudamos pilares teóricos e conceituais, história, técnicas artísticas... Mas também trabalhamos juntos na organização e limpeza dos espaços, realizamos trabalhos artísticos coletivos, participamos ativamente das constantes avaliações e do processo de construção do curso, sempre em movimento, em transformação. Todo o curso teve uma dimen- 
são bastante coletiva, onde todos(as) éramos necessários(as) e muito respeitados em nossas individualidades, percepções e opiniões.

O Arte no Campo durou dois anos inteiros e ele teve muito de Marcia Pompeo. Marcia esteve sempre presente e foi muito generosa, mas também não tinha medo de endurecer diante das situações que julgava necessárias e importantes para garantir o andamento do curso. Com essa sua personalidade, conseguiu realizar muitas coisas, dentre elas, o próprio curso de Arte no Campo, que não construiu sozinha, mas liderou estando sempre a frente de sua condução.

Pessoas como Marcia Pompeo reafirmam a importância da Universidade ir além de seus muros e estabelecer uma relação dialógica com as comunidades, nesse espaço potente onde diversos saberes podem se encontrar, modificando e enriquecendo a vida dos envolvidos (direta ou indiretamente) nos projetos, sejam eles acadêmicos, ou integrantes da comunidade. Assim aconteceu comigo.

Dois anos e meio após a finalização desta residência agrária, fiquei sabendo que havia sido aberto um concurso público para professor(a) efetivo(a) de teatro em um curso de graduação em Educação do Campo na Universidade Federal do Tocantins - UFT. Como no convite que Marcia me fez para ler o edital do curso de especialização, senti que o edital deste concurso também "tinha a minha cara". Inscrevi-me, passei pelo processo seletivo e fui selecionada. Sentia-me grata.

Nas palavras de Freire, "foi exatamente porque nos tornamos capazes de dizer o mundo, na medida em que o transformávamos, em que o reinventávamos, que terminamos por nos tornar ensinantes e aprendizes. Sujeitos de uma prática que se veio tornando política, gnosiológica, estética e ética." (2000, p. 19). Assim, tornei-me educadora numa instituição federal de ensino superior.

Tinha consciência do quanto Marcia Pompeo havia sido importante, para não dizer determinante, em minha caminhada. Ela não foi a única pessoa importante nesta trajetória, mas, sem ela, certamente teria tomado outros rumos. 
Liguei para Marcia para contar de minha conquista e agradecê-la. Disse-lhe de sua importância e de sua parcial responsabilidade sobre meus méritos. Ela emocionou-se e me agradeceu o gesto. Meses depois ela, infelizmente, veio a falecer. Agora, venho eu a público, através deste relato, expressar um pouco da importância e força desta mulher chamada Marcia Pompeu Nogueira, e de como sua chama segue viva e latente em nossas memórias e caminhos.

Um homem da aldeia de Neguá, no litoral da Colômbia, conseguiu subir aos céus. Quando voltou, contou. Disse que tinha contemplado, lá do alto, a vida humana. E disse que somos um mar de fogueirinhas.

- O mundo é isso - revelou. - Um Monte de gente, um mar de fogueirinhas.

Cada pessoa brilha com luz própria entre todas as outras. Não existem duas fogueiras iguais. Existem fogueiras grandes e fogueiras pequenas e fogueiras de todas as cores. Existe gente de fogo sereno, que nem percebe o vento, e gente de fogo louco, que enche o ar de chispas. Alguns fogos, fogos bobos, não alumiam nem queimam; mas outros incendeiam a vida com tamanha vontade que é impossivel olhar para eles sem pestanejar, quem chegar perto pega fogo. (Eduardo Galeano) 


\section{REFERÊNCIAS}

BONDÍA, Jorge Larrosa. Notas sobre a experiência e o saber da experiência. In: GERALDI, C. M. G.; RIOLFI, C. R.; GARCIA, M. F.(orgs.). Escola viva: Elementos para a construção de uma educação de qualidade social. Campinas, SP: Mercado das Letras, 2004.

FREIRE, Paulo. Política e Educação. 4 ed. São Paulo: Cortez, 2000.

GALEANO, Eduardo. O livro dos abraços. Trad. Eric Nepomuceno. Porto Alegre: L\&MP, 2006.

MANO, Maria Amélia. Ensaio sobre a Gratidão. In: MANO, Maria Amélia Medeiros; PRADO, Ernande Valentin do (Orgs.). Vivências de Educação Popular na Atenção Primária à Saúde. São Carlos: EdUFASCar, 2010. p. 61-71.

NOGUEIRA. Márcia Pompeo. Clubes de teatro na formação de professores. Anais do XVII CONFAEB - Congresso da Federação de Arte Educadores do Brasil, 2007. 